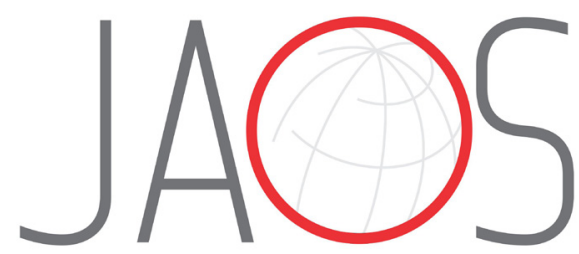

JOURNAL OF APPLIED ORAL SCIENCE

\title{
Determination of the effective anticandidal concentration of denture cleanser tablets on some denture base resins
}

\section{Abstract}

Yeliz HAYRAN ${ }^{1}$

Işı| SARIKAYA ${ }^{1}$

Ali AYDIN ${ }^{2}$

Yadel Hazır TEKIN ${ }^{1}$
Submitted: February 16, 2017 Modification: July 3, 2017 Accepted: August 2, 2017
Objective: Although the effectiveness of chemical cleansing against Candida albicans biofilm has been shown, the effective concentration of denture cleanser tablets has not been studied. The aim of this study was to assess the effect of three denture materials against Candida albicans biofilm and to determine effective concentrations of denture cleanser tablets. Material and methods: The surface-roughness of Acron-hi ${ }^{\mathrm{TM}}, \mathrm{QC}-20^{\mathrm{TM}}$ and Deflex $^{\mathrm{TM}}$ ( $n=45$ per resin) resins was standardized by using a profilometer and their contact angle or surface free energy was calculated. C. albicans biofilm was formed on all three resins and were treated with Polident 3 $\min ^{\mathrm{TM}}$, Corega ${ }^{\mathrm{TM}}$ and Fittydent ${ }^{\mathrm{TM}}$ cleanser solutions at various concentrations and both resin-biofilm and cleanser-biofilm interest were determined by using a MTT protocol according to the European Committee on Antimicrobial Susceptibility Testing's antifungal susceptibility testing (AFST-EUCAST). Scanning electron microscopy was used to compare the efficacy of different resin materials against $C$. albicans biofilm. Anticandidal activity and surface free energy statistical parameters were calculated by using 3-way and 1-way ANOVA, respectively $(p<0.05)$. Results: Polident $3 \mathrm{~min}^{\mathrm{TM}}$ and Corega ${ }^{\mathrm{TM}}$ tablets significantly inhibited $(p<0.05)$ the proliferation of $C$. albicans against all denture resins at $27-37 \mathrm{mg} / \mathrm{mL}$. Scanning electron microscopy results indicated that there was no significant difference among resin specimens regarding biofilm formation on dentures. We failed to find a significant relationship between surface free energy and the anticandidal effect of resin types. However, the polarity value of the resins was statistically associated with their anticandidal activity. Conclusions: The polarity of the resins, the concentrations of tablets and the chemical content of the cleanser may directly affect $C$. albicans biofilm formations. Polident $3 \mathrm{~min}^{\mathrm{TM}}$ and Corega ${ }^{\mathrm{TM}}$ tablets should be suggested for patients who use any denture resin types, whereas the Fittydent ${ }^{\mathrm{TM}}$ tablet should only be proposed for those who use Deflex ${ }^{\mathrm{TM}}$, when two tablets are dropped into $150 \mathrm{~mL}$ water.

Keywords: Candida albicans. Surface properties. Denture cleansers. Denture bases.
Corresponding address: Yeliz Hayran Department of Prosthodontics Faculty of Dentistry - Gaziosmanpaşa University.
Box 60100 - Tokat - Turkey.
Phone: +9 3562124222 - Fax: +9 3562124225 Faculty of Dentistry - Gaziosmanpaşa University.
Box 60100 - Tokat - Turkey. e-mail: yeliz_hayran@yahoo.com yeliz.hayran@gop.edu.tr
${ }^{1}$ Gaziosmanpaşa University, Faculty of Dentistry, Department of Prosthodontics, Tokat, Turkey. ${ }^{2}$ Gaziosmanpasa University, Faculty of Science and Art, Department of Molecular Biology \& Genetics, Tokat, Turkey. 


\section{Introduction}

Denture stomatitis is a common infection of the oral mucosa in denture wearers and Candida albicans is the most significant etiological agent of denture stomatitis ${ }^{15,20}$. C. albicans is an obstinate infection agent which is difficult to eliminate once it has been colonized as a complex biofilm formation $6,8,14,15$. The surface of acrylic resin denture base provides an ideal environment for microorganisms and biofilm formation, thus the development of C. albicans in such places $4,6,9,14,15,20,24,27,29$. The risk of denture stomatitis increases in the presence of poor oral and denture hygiene, misfit prosthesis and night wear of removable dentures ${ }^{4,14,20,24}$. It has been found that repeated inhalation and ingestion of microorganisms adhering to the mucosa and denture base can be a reason for various infections in patients with immune deficiency or in those receiving treatment ${ }^{20}$. Therefore, oral and denture hygiene is very important to remove microorganisms. Two methods are recommended to remove denture biofilm: mechanical or chemical, or a combination of both. Although the efficiency of mechanical methods in removing denture biofilm or microorganisms has been clearly shown, some people do not have the ability to apply sufficient denture hygiene ${ }^{14,21}$. This is especially the case for patients with limited motor capacity who have difficulty in cleaning the prosthesis with mechanical methods. To use unsuitable toothbrush with a dentifrice may also lead to surface roughness, which allows more microbial colonization ${ }^{14}$. The effectiveness of chemical cleansing to control C. albicans biofilm is shown in many studies, and denture cleansers are recommended for reducing biofilm formation on the dentures for these patients ${ }^{4,6}$. These cleansers are available as commercial products, and they usually include alkaline peroxides ${ }^{19,23}$, sodium hypochlorite ${ }^{5,29}$, acids ${ }^{29}$, enzymes ${ }^{19}$, and neutral enzymatic peroxides solution 4-6,15,19. Effervescent tablets yielding an alkaline peroxide dilution with water are the preferred denture cleansers ${ }^{3,7,13,16,18,22}$ because they can easily provide enough cleansing without causing damage to surface resins ${ }^{26}$. These effervescent tablets act differently as mechanisms against microbial flora. For example, Polident $3 \mathrm{~min}^{\mathrm{TM}}$, one of the cleanser effervescent tablets, achieves chemical cleaning by using the release of oxygen from a neutral enzymatic peroxide solution ${ }^{4-6,15,19}$. However, the biofilm layer often cannot be completely removed from the resin surface and a number of viable cells remain on resins ${ }^{29}$. According to our knowledge, three significant factors - resin types with physicochemical features, cleanser types and cleanser concentrations - can be suggested to explain this situation.

PMMA, one of the resins, is the most commonly used denture base material due its favourable mechanical, physical and aesthetic properties. However, it has some disadvantages, such as low flexural and impact strength ${ }^{10}$. Therefore, alternative materials, such as polyamide thermoplastic resin and chemical modification of PMMA with high impact resin, have been developed to achieve better mechanical properties of denture base materials. High impact acrylic resin has a high resistance against unexpected falls ${ }^{25}$. Also, polyamide thermoplastic resin is more elastic than PMMA. Polyamide resins are especially preferred for patients with tissue allergies to $\mathrm{PMMA}^{30}$. Thus, polyamide thermoplastic resin and high impact resin are suggested for patients with a tendency to drop their prosthesis, such as elderly and handicapped denture wearers.

In addition, one of the significant physicochemical features of resin surface is the surface free energy (SFE) resulted from the asymmetry between the energies of the molecules at the surface and in the bulk of resin, since the molecules at the surface of a solidphase material are under the pressure of a one-side force, whereas in the bulk material, molecules do not have net forces due to being under equal pressure from every direction. Surface free energy (SFE) and surface roughness $(\mathrm{Ra})$ both have important roles in the first adhesion of microorganisms ${ }^{2,17}$. Some studies showed that $\mathrm{Ra}$ and, to a lesser extent, SFE of resins, along with environmental conditions, are responsible for the C. albicans biofilm formation on the resin surface ${ }^{2,17}$. However, the effect of the Ra on biofilm formations can be minimized and standardized by polishing resin surfaces to see the net effect from the SFE.

The effectiveness of various denture cleanser tablets in removing $C$. albicans biofilm formation on denture acrylic resin surfaces has been evaluated in other studies $4,6,15,29$. These studies showed a significant decrease in the amount of $C$. albicans after exposure to different cleansers ${ }^{4,6,14,29}$.

Cleanser concentrations may also play a significant role in the removal of $C$. albicans biofilm from resin surfaces. To the best of our knowledge, this is the first work that describes the correlation between cleanser 
concentration and biofilm removal from denture surface.

Thus, the purpose of this study was to evaluate the effect of different resin types on $C$. albicans biofilm formation and to determine the effective concentrations of commercial denture cleansing tablets to remove biofilm formation according to the manufacturers' recommendation times. Null hypotheses were that 1) there is no significant difference between the amount of C. albicans inhibited by chemical cleanser tablets in MTT assay; 2) There is no significant difference between the amount of $C$. albicans bind to resin types in scanning electron microscope (SEM) analyser and MTT assay; 3) There is no significant interaction between the amount of $C$. albicans inhibited by resin types, tablet types and tablet concentrations in all assays; 4) There would be no differentiation among the concentration of chemical cleanser in decreasing Candida levels; and 5) The amount of C. albicans adhesion would not be associated with resin polarity.

\section{Material and methods}

\section{Specimen preparation}

Two types of heat-polymerized PMMA resin and one type of thermoplastic polyamide resin were used for the fabrication of specimens ( $n=45$ per resin). All denture base specimens were prepared according to the manufacturers' instructions. Circular wax pattern discs with dimensions of $10 \mathrm{~mm}$ in diameter and 2 $\mathrm{mm}$ in thickness were prepared using a stainless steel mould ${ }^{5,6}$. Wax discs were invested in denture flasks followed by a compression moulding technique for conventional heat-polymerized acrylic resin (Q-type) (QC-20, Dentsply, Addlestone, UK) and high-impact heat-polymerized acrylic resin (A-type) (Acronhi, Kemdent, Swindon, UK); then, wax discs were invested in injection flasks followed by a rapid injection technique for polyamide thermoplastic resin (D-type) (Deflex classic SR, Buenos Ares, AR) and afterwards melted with boiling water. The heat-polymerized acrylic resins were then packed into the mould, and the metal flasks were placed in a boiler unit for polymerization. The infection flask and thermoplastic polyamide resin cartridge were placed in the device, and the resin was injected into the mould. All flasks were allowed to cool down for $2 \mathrm{~h}$. All specimens were immersed in distilled water for $24 \mathrm{~h}$ for residual monomer release ${ }^{28}$.
Following this, specimens were labelled on one surface. Respectively, one side of each specimen was ground wet with 600,800 and 1,000 grit emery paper to standardize surface roughness, which was measured using a profilometer (Taylor Hobson, Surtronic 25, Leicester, UK). Evaluation length and range were calibrated at $1.25 \mathrm{~mm}$ and $100 \mu \mathrm{m}$, respectively. Three readings were made for each specimen, and a mean value was calculated. For all resins, surface roughness (Ra) was standardized at $0.3 \pm 0.02 \mu \mathrm{m}$. After surface roughness measurements were completed, the specimens were ultrasonically (Pro-Sonic 600, Sultan Healthcare, Hackensack, NJ) cleansed in sterilized distilled water at $50^{\circ} \mathrm{C}$, at $28 \mathrm{kHz}$ frequency for 10 min. Thus, any contaminants or artefacts from the surfaces were removed before the measurement of surface free energy (SFE).

\section{Contact angle and surface free energy measurements}

For the contact angle and SFE calculation, three liquids with well-established polar and dispersive components of surface tension were chosen. Distilled water, diiodomethane and formamide were used with the sessile drop technique on the surface of the specimens for measurement. It is known that water and formamide are polar and that diiodomethane is nonpolar. Therefore, the water-formamide pair gave accurate values for polar components, and the waterformamide-diiodomethane combination gave better results in the calculations of both polar components and dispersive components. Dispersive, polar, acidic and basic components of the SFE and the SFE of denture resin surfaces were calculated using five different methods: the acid-base approach; equation of state; OWRK/Fowkes; Wu; and Zisman. Contact angle measurements were obtained using a KSV Attension Theta Lite Optical Tensiometer (Helsinki, FI). Five drops were measured on each sample at room temperature. SFE was calculated using contact angle values.

\section{Fungal cultures and growth conditions}

The $C$. albicans (ATCC 1023) strain was maintained on solid Sabouraud dextrose agar at $35^{\circ} \mathrm{C}$ in an incubator. Colonial growth after $24 \mathrm{~h}$ was $1-5 \times 10^{6}$ cells, measured with the help of trypan blue or a Neubauer chamber and pipetted of the polystyrene microtiter plates with 24 wells containing RPMI-2\% glucose liquid medium and then allowed to grow at 
$35^{\circ} \mathrm{C}$ for $48 \mathrm{~h}$ in a shaker incubator at $150 \mathrm{rpm}$. The C. albicans cell counting with the Neubauer chamber was also standardized according to McFarland turbidity standards for experimental confirmation.

\section{Test tablets}

Tablets of the alkaline peroxide denture cleansers Corega $^{\mathrm{TM}}$ and Fittydent ${ }^{\mathrm{TM}}$ and the neutral peroxide enzymatic denture cleanser Polident $3 \mathrm{~min}^{\mathrm{TM}}$ were obtained from the manufacturers and used as received. The tablet contents (Figure 1) were reconstituted by using distilled water, and the cleanser working solution was used immediately. One test tablet is approximately $2.5 \mathrm{~g}$. For cleanser working solutions, tablets were dissolved in a concentration ranging from $1-5$ tablets/150 $\mathrm{mL}$ of warm distilled water, corresponding to $16,32,48,64$ and $80 \mathrm{mg} /$ $\mathrm{mL}$, respectively.

\section{Susceptibility testing}

An MTT assay gives an accurate estimate of the number of viable cells. Thus, we performed an MTT assay according to AFST-EUCAST guidelines. An MTT stock solution ( $5 \mathrm{mg}$ of $\mathrm{MTT} / \mathrm{mL}$ of distilled water) was filter sterilized and kept at $-20^{\circ} \mathrm{C}$ until use. First, the biofilm was grown as described previously. After a 48-h incubation period, the old medium in the wells was carefully removed, and the cells were treated with $200 \mu \mathrm{L}$ of the cleanser solutions of Polident 3 $\min ^{\mathrm{TM}}$, Corega ${ }^{\mathrm{TM}}$, and Fittydent ${ }^{\mathrm{TM}}$ for 3, 5, and 5 min, respectively, at final concentrations of $16,32,48,64$, and $80 \mathrm{mg} / \mathrm{mL}$. Afterwards, cleanser solutions were replaced with fresh RPMI-2\% glucose liquid medium containing MTT (final concentration, $0.5 \mathrm{mg} / \mathrm{mL}$ ). The mixture was incubated for $4 \mathrm{~h}$ on a shaker incubator $\left(150 \mathrm{rpm}\right.$ at $35^{\circ} \mathrm{C}$ ). After the incubation period, 180 $\mu \mathrm{L}$ of the medium were removed, $30 \mu \mathrm{L}$ of Sorenson's buffer and $150 \mu \mathrm{L}$ of DMSO were added to the well, and the plate was vortexed for $5 \mathrm{~min}$. The optical density of sample and blanks (DMSO with Sorenson's buffer) was measured with a spectrophotometer at $560 \mathrm{~nm}$, with $690 \mathrm{~nm}$ as a reference interval. The percentage of viability was calculated using the Excel software. Each experiment was repeated at least three times for each of the cleanser tablets.

\section{Calculation of $\%$ inhibition and $\mathrm{IC}_{50}$}

The half maximal inhibitory concentration $\left(\mathrm{IC}_{50}\right.$ ) represents the required concentration of an agent to inhibit a biological process by $50 \%$ in vitro. The MTT assay results were reported as the percentages of viability of the test substances. The $\mathrm{IC}_{50}$ of the test compounds was calculated using these percentages of viability with the help of the XLfit5 software (IDBS) and expressed in $\mu \mathrm{g} / \mathrm{mL}$ at $95 \%$ confidence intervals.

\section{Determination of the minimum inhibitory concentration}

The minimum inhibitory concentration (MIC) of tablets was examined using $C$. albicans growing in the RPMI-2\% glucose liquid medium. A 24-well microtiter plate was used for this measurement. Test compounds $(16,32,48,64$, and $80 \mathrm{mg} / \mathrm{mL})$ together with different resin types bearing $C$. albicans biofilm were incubated at $20-25^{\circ} \mathrm{C}$ for $3-5 \mathrm{~min}$ in air. Any plate well showing no visible growth was recorded as an MIC value.

\section{Scanning electron microscopy}

Scanning electron microscopy (SEM) was conducted using biofilms of $C$. albicans formed on the surface of resins. Biofilms were treated with the test compounds with the $\mathrm{IC}_{50}$ concentrations for 3-5 min. Cells were then washed twice with DPBS and fixed in $2.5 \%$ glutaraldehyde in a phosphate buffer for $16 \mathrm{~h}$ and, shortly after, refixed in $2 \%$ osmium tetroxide for $2 \mathrm{~h}$. Then, they were dehydrated through ethanol rinses $(30,50,90,95$, and $100 \%)$ and mounted and sputtercoated with gold. Sample surfaces were examined

\begin{tabular}{|c|c|c|}
\hline Denture cleanser & Manufacturer & Ingredients \\
\hline Corega $^{\mathrm{TM}}$ & $\begin{array}{l}\text { GlaxoSmithKline Healthcare, } \\
\text { Istanbul, Turkey }\end{array}$ & $\begin{array}{c}\text { Sodium bicarbonate, citric acid, potassium monopersulfate, sodium carbonate, } \\
\text { sodium carbonate peroxide, TAED, sodium benzoate, PEG-180, sodium lauryl } \\
\text { sulfoacetate, VP/VA copolymer, aroma, subtilisin, Cl 42090, Cl } 73015\end{array}$ \\
\hline Fittydent $^{\mathrm{TM}}$ & $\begin{array}{c}\text { Fittydent International } \mathrm{GmbH} \text {, } \\
\text { Pinkafeld, Austria }\end{array}$ & $\begin{array}{l}\text { Sodium perborate, sodium bicarbonate, potassium monopersulfate, trisodium } \\
\text { phosphate, PEG-240, sulfamic acid, PVP, TAED, silica, sodium methyl oleoyl } \\
\text { taurate, cellulose-lactose, colour C.I. } 42090 \text {, aroma }\end{array}$ \\
\hline Polident $3 \min ^{\mathrm{TM}}$ & $\begin{array}{l}\text { GlaxoSmithKline Healtcare, } \\
\text { Moon Township, PA }\end{array}$ & $\begin{array}{c}\text { Sodium bicarbonate, citric acid, potassium monopersulfate, sodium carbonate, } \\
\text { sodium percarbonate, TAED, sodium benzoate, PEG-180, sodium lauryl } \\
\text { sulfoacetate, VP/VA copolymer, aroma, blue } 1 \text { aluminum lake, blue } 2 \text {, yellow } 5 \\
\text { aluminum lake, yellow } 5\end{array}$ \\
\hline
\end{tabular}

Figure 1- The chemical content of the Corega ${ }^{\mathrm{TM}}$, Fittydent ${ }^{\mathrm{TM}}$ and Polident 3 min $^{\mathrm{TM}}$ 
using SEM (Zeiss LEO 440, Cambridge, UK).

\section{Statistical analysis}

The statistical significance of differences was determined by the three-way analysis of variance (three-way ANOVA) followed by Tukey's test. Data that did not show homogeneity variance were analysed by the non-parametric Kruskal-Wallis test. The SPSS for Windows computer program was used for statistical analyses. Results of SFE were reported as mean values $\pm S D$ of three independent assays, and differences among groups were considered to be significant at $p<0.05$.

\section{Results}

Anticandidal effects of the three cleansing tablets against $C$. albicans biofilm were initially screened using the MTT viability assay. According to MTT test results, Polident $3 \mathrm{~min}^{\mathrm{TM}}$ and Corega ${ }^{\mathrm{TM}}$ tablets exhibited strong anticandidal effects on $C$. albicans biofilm on all denture resin at nearly 2 tablets $/ 150 \mathrm{~mL}$ of water concentration $(p<0.05)$, whereas Fittydent ${ }^{\mathrm{TM}}$ had only anticandidal effects against the biofilm on D-type resin at nearly $21 / 2$ tablets/ $150 \mathrm{~mL}$ of water concentration (Figure 2 ) (Table 1 ). The anticandidal activity of the Corega ${ }^{\mathrm{TM}}$ was higher on A- and D-type resins compared to Polident ${ }^{\mathrm{TM}}$ and Fittydent ${ }^{\mathrm{TM}}$. The effective concentrations of Corega $^{\mathrm{TM}}$ tablets were found to be $30.42 \mathrm{mg} / \mathrm{mL}, 27.37$ $\mathrm{mg} / \mathrm{mL}$ and $30.52 \mathrm{mg} / \mathrm{mL}$ (approximately 2 tablets) on the A-, D- and Q-type resins, respectively (Table 1A). However, Polident $3 \mathrm{~min}^{\mathrm{TM}}$ anticandidal activity was strongest on the Q-type denture $(22.78 \mathrm{mg} / \mathrm{mL}$, approximately $1 \frac{1}{2}$ tablet). The effective concentrations of Polident $3 \mathrm{~min}^{\mathrm{TM}}$ tablets were $37.62 \mathrm{mg} / \mathrm{mL}, 36.44$ $\mathrm{mg} / \mathrm{mL}$ (approximately $21 / 2$ tablets), and $22.78 \mathrm{mg} / \mathrm{mL}$ (approximately $1 \frac{1}{2}$ tablet) on the $\mathrm{A}^{-}, \mathrm{D}-$, and $\mathrm{Q}$-type resins, respectively. The effective concentrations of Fittydent $^{\mathrm{TM}}$ were $74.89 \mathrm{mg} / \mathrm{mL}$ (approximately $41 / 2$ tablets), $38.19 \mathrm{mg} / \mathrm{mL}$ (approximately $2 \frac{1}{2} 2$ tablets) and $64.41 \mathrm{mg} / \mathrm{mL}$ (approximately 4 tablets) on A-, D-, and Q-type resins, respectively. $\mathrm{IC}_{50}$ values to be used in subsequent studies were determined by performing the MTT assay, as indicated in Table $1 \mathrm{~A}$.

After an incubation time, the inhibition zone (optically clear) was produced by each cleansing solution, and the lowest concentration at which there

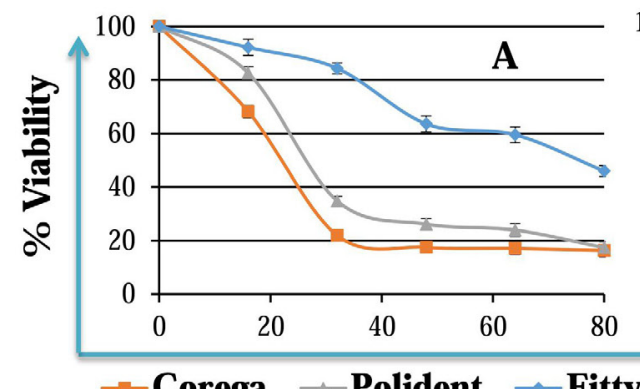

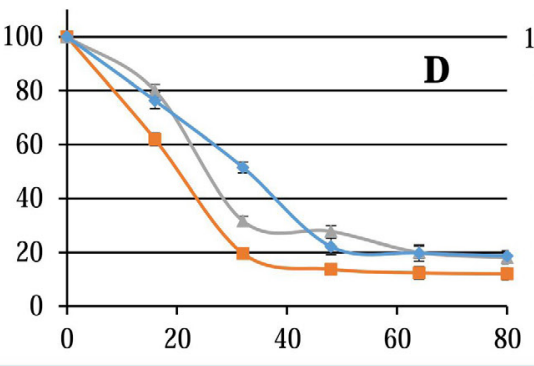

itty

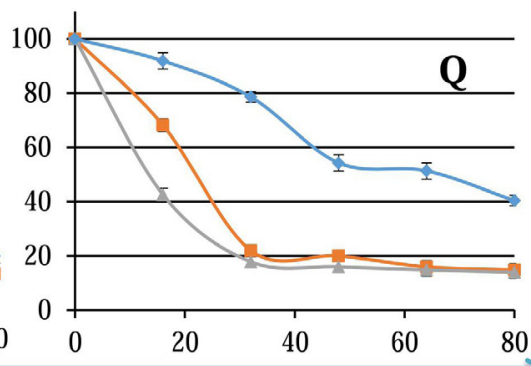

Concentration $(\mu \mathrm{g} / \mathrm{mL})$

Figure 2- The effects of Corega, Polident 3 min or Fittydent tablets on the viability of Candida albicans biofilm on the surface A-, Q-, or D-type resin specimens. Exponentially growing cells on denture surface were incubated with Corega, Polident 3 min or Fittydent cleansing solutions for 5,3 , and 5 min, respectively, and the cell viability was measured by the MTT assay. Percent viability was reported as mean values \pm SEM of three independent assays $(p<.05)$

Table 1- A) IC50 values for Corega, Polident 3 min or Fittydent cleansing tablets. B) MIC values for Corega, Polident 3 min or Fittydent cleansing tablets

\begin{tabular}{cccc}
\hline & A & & \\
\hline Inhibitor concentration $(\mathrm{IC} 50 \mathrm{mg} / \mathrm{mL})$ & A & D & Q \\
Corega & 30.42 & 27.37 & 30.52 \\
Polident 3 min & 37.62 & 36.44 & 64.41 \\
\hline Fittydent & 74.89 & 38.19 & \\
\hline & B & & Q \\
\hline Minimum inhibitory concentration $(\mathrm{mg} / \mathrm{mL})$ & A & D & 45 \\
Corega & 45 & 45 & 45 \\
Polident 3 min & 45 & 45 & $80<$ \\
\hline Fitty & $80<$ & 50 & \\
\hline
\end{tabular}


was no visible zone of inhibition was taken as the MIC. The experiment was repeated three times, and the MIC values are presented in Table 1B. As shown in Table 1B, Corega ${ }^{\mathrm{TM}}$ and Polident $3 \mathrm{~min}^{\mathrm{TM}}$ had a higher inhibitory effect against biofilm.

Statistical analysis was achieved by using a threeway ANOVA test and showed significant difference in the mean values of resin types, tablet types, and tablet concentrations. The three-way ANOVA was run on a sample of 135 resins to examine the effect of resin type, tablet type or tablet concentrations against biofilm. There was a statistically significant three-way interaction between resin type, tablet type and tablet concentrations, $F(16,90)=18.81, p=.000$ (Table $2 \mathrm{~A}$ ).
When calculating the two-way ANOVA, the resin types by tablet types $(F(4,90)=324.79, p=.000)$, resin types by tablet concentrations $(F(8,90)=16.56, p=.000)$, and tablet types by tablet concentrations $(F(8$, $90)=80.96, p=.000$ ) are statistically significant (Table 2A). Application of Tukey's HSD multiple comparisons test showed a statistically significant difference among all test groups (Tables 2B and 2C) (mean difference is " $*$ " indicating significant difference among groups).

The plot of the mean "viability" score for each combination of groups of "resins" and "tablets" are plotted in a line graph at all concentrations, as shown in Figure 3.

The adhesion and the spreading of cells on surfaces

Table 2- A) Tests of Between-Subjects Effects (Dependent Variable:Viability). B) Viability\&Tukey HSD for resin types. C) Viability\&Tukey HSD for cleansing tablets

\begin{tabular}{|c|c|c|c|c|c|}
\hline \multicolumn{6}{|c|}{ A } \\
\hline Source & $\begin{array}{l}\text { Type III Sum of } \\
\text { Squares }\end{array}$ & df & Mean Square & $\mathrm{F}$ & Sig. \\
\hline Corrected Model & a88651.08 & 44 & 2014.80 & 408.41 & .000 \\
\hline Intercept & 180547.92 & 1 & 180547.92 & 36597.55 & .000 \\
\hline Resin type & 2953.44 & 2 & 1476.72 & 299.34 & .000 \\
\hline Tablet type & 22468.55 & 2 & 11234.27 & 2277.22 & .000 \\
\hline Concentration & 51486.42 & 4 & 12871.60 & 2609.11 & .000 \\
\hline Resin type * Tablet type & 6409.1 & 4 & 1602.27 & 324.79 & .000 \\
\hline Resin type * Concentration & 653.45 & 8 & 81.68 & 16.56 & .000 \\
\hline Tablet type * Concentration & 3195.23 & 8 & 399.4 & 80.96 & .000 \\
\hline $\begin{array}{l}\text { Resin type * Tablet type * } \\
\text { Concentration }\end{array}$ & 1484.90 & 16 & 92.81 & 18.81 & .000 \\
\hline Error & 444.00 & 90 & 4.93 & & \\
\hline $\begin{array}{c}\text { a. R Squared }=.995 \text { (Adjusted } \\
\text { Squared }=.993 \text { ) }\end{array}$ & & & & & \\
\hline \multicolumn{6}{|c|}{ B } \\
\hline (I) Resin type & (J) Resin type & $\begin{array}{l}\text { Mean Difference } \\
(I-J)\end{array}$ & Std. Error & Sig. & \\
\hline \multirow[t]{2}{*}{$A$} & $\mathrm{D}$ & $11,40^{*}$ & 0.468 & .000 & \\
\hline & Q & $6,69^{*}$ & 0.468 & .000 & \\
\hline \multirow[t]{2}{*}{$\mathrm{D}$} & $A$ & $-11,40^{*}$ & 0.468 & .000 & \\
\hline & $\mathrm{Q}$ & $-4,71^{*}$ & 0.468 & .000 & \\
\hline \multirow[t]{2}{*}{$Q$} & $A$ & $-6,69^{*}$ & 0.468 & .000 & \\
\hline & D & $4,71^{*}$ & 0.468 & .000 & \\
\hline \multicolumn{6}{|c|}{ C } \\
\hline (I) Tablet type & (J) Tablet type & $\begin{array}{l}\text { Mean Difference } \\
(I-J)\end{array}$ & Std. Error & Sig. & \\
\hline \multirow[t]{2}{*}{ Corega } & Polident & $-4,31^{*}$ & 0.468 & .000 & \\
\hline & Fitty & $-29,27^{*}$ & 0.468 & .000 & \\
\hline \multirow[t]{2}{*}{ Polident } & Corega & $4,31^{*}$ & 0.468 & .000 & \\
\hline & Fitty & $-24,96^{*}$ & 0.468 & .000 & \\
\hline \multirow[t]{2}{*}{ Fitty } & Corega & $29,27^{*}$ & 0.468 & .000 & \\
\hline & Polident & $24,96^{*}$ & 0.468 & .000 & \\
\hline
\end{tabular}


were investigated using SEM. As shown in Figure 4, obvious cell spreading changes were not observed in the treated cells compared to the untreated cells. The biofilm exposed to the five concentrations of cleansing tablets did not exhibit significantly greater adhesion strength. This situation was not consistent with the results of the above mentioned MTT assays.

Also, we found that surface characteristics among the thermoplastic polyamide resin (D-type) and the PMMAs (Q-type and A-type) may cause the formation of the $C$. albicans biofilm layer in different confluences on resin types. In fact, we observed that the $C$. albicans biofilm layer effectively spread on the Aand Q-type resins by penetrating into their notched surfaces, whereas this was not found in the D-type resin (Figure 4, IV-VI).

Results of SFE analysis and the analysis of its components are shown in Tables 3A-3D. The dispersive and polar components of Q-, A-, and D-type resins were found to be $35.19-4.58 \mathrm{~mJ} / \mathrm{m}^{2}$ for distilled water, $32.71-3.88 \mathrm{~mJ} / \mathrm{m}^{2}$ for diodomethane, and 34.72-2.99 $\mathrm{mJ} / \mathrm{m}^{2}$ for formamide. According to the acid-base approach, SFE values of $\mathrm{Q}^{-}, \mathrm{A}^{-}$, and $\mathrm{D}$-type resins were $39.77,36.60$, and $37.71 \mathrm{~mJ} / \mathrm{m}^{2}$, respectively. Q-type resin exhibited the highest SFE value $(p<0.05)$, whereas the lowest values were found for A-type resin in all methods $(p<0.05)$ (Table $3 B$ and 3C). Generally, differences in the SFE of these resins were identified for all methods $(p<0.05)$. Polarity values of $Q_{-}$, A- and D-type resins were $0.13,0.12$, and 0.08 , respectively.

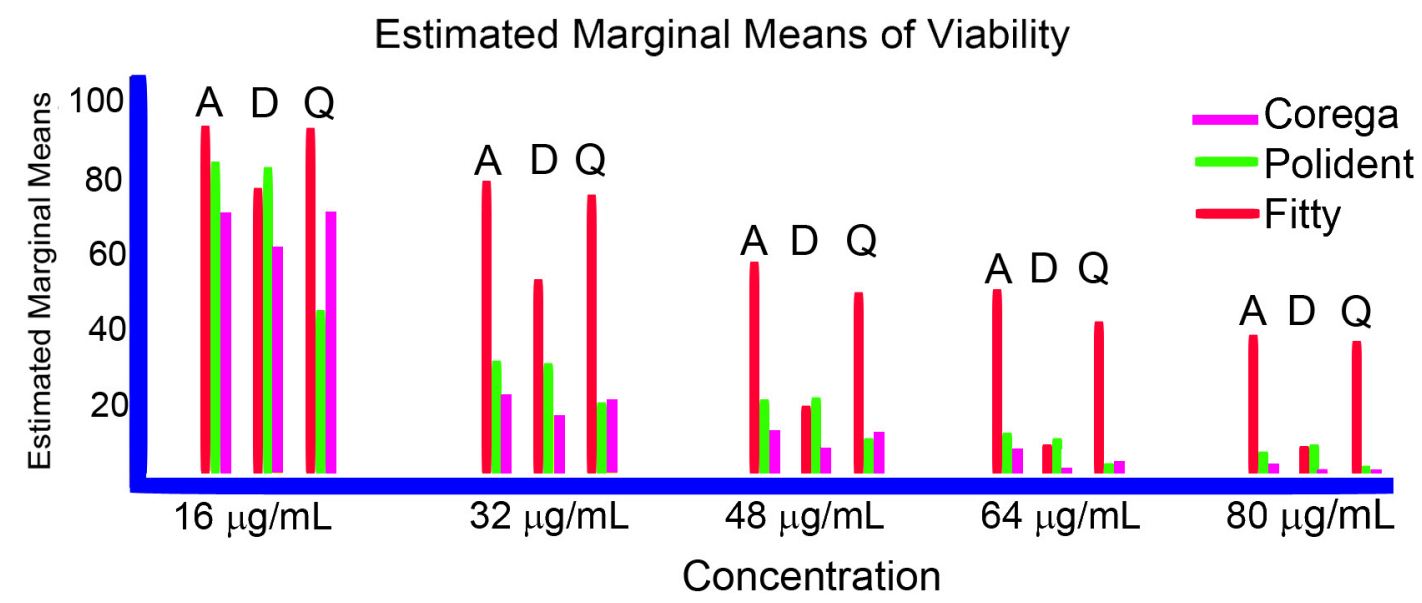

Figure 3- The graphics illustrated that an interaction effect is among resin*tablet at all concentration
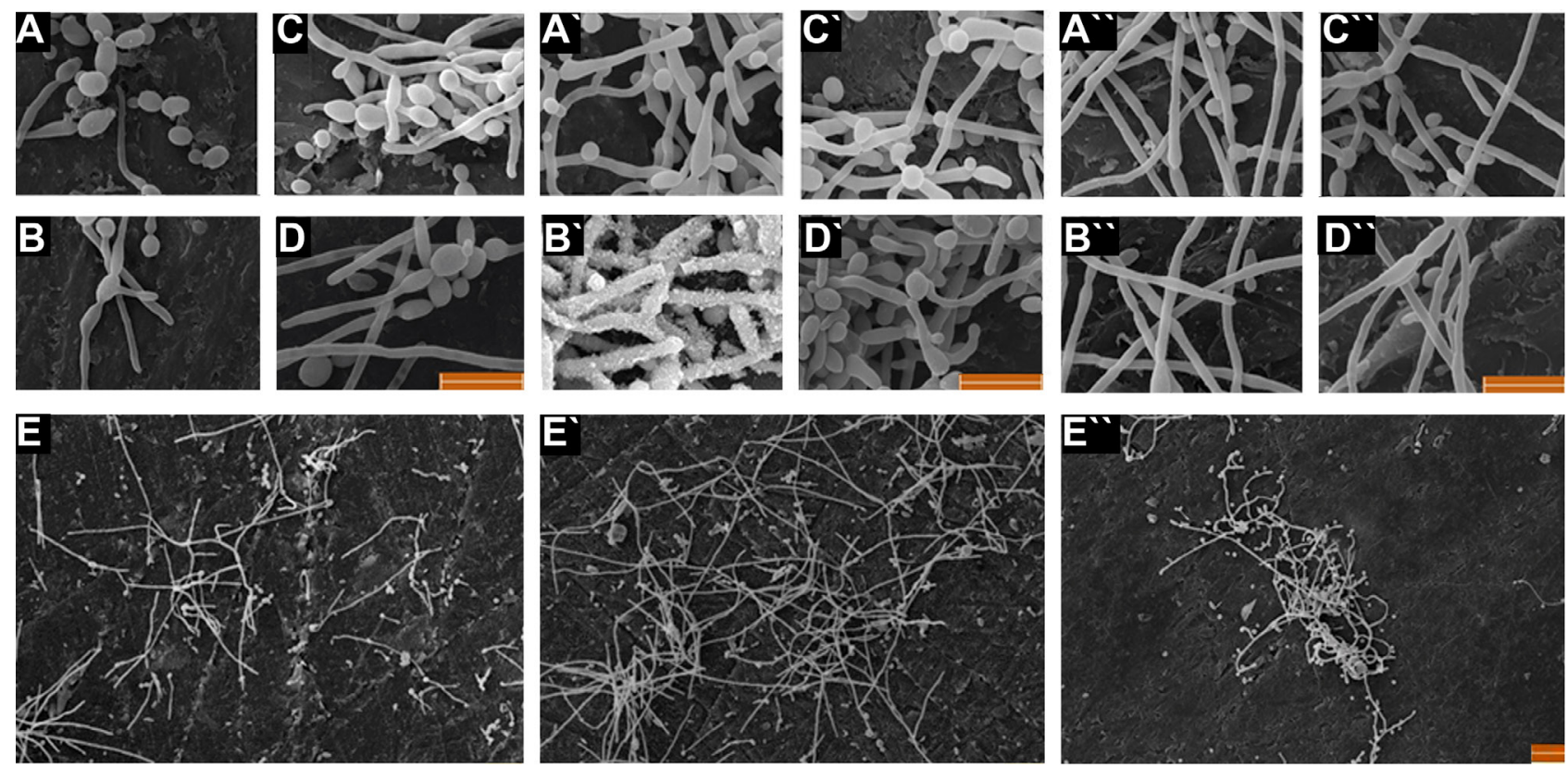

Figure 4- Scanning electron microscopy images of $A, B, C, D$, and $E$ for A-type resin; $A^{`}, B^{\prime}, C^{\prime}, D^{`}$ and $E^{`}$ for $D$ type resin and $A^{\prime \prime}, B^{\prime \prime}$, $C$ C, D“ and E” for Q-type resin are Corega-tested surface, Polident-tested surface, Fittydent-tested surface, Control and Surface type, respectively. Bar is $10 \mu \mathrm{m}$. A- and Q-type resins showed more notched surface with deeply fissure (E and $\left.E^{\prime \prime}\right)$. A detailed analysis of the $\mathrm{D}$ (E')-type resin surface displayed smooth and regular texture 
Table 3- A) Acidic, Basic Components of Surface Free Energies of Test Liquids used in this work $\left(\mathrm{mJ} / \mathrm{m}^{2}\right)$. B) Surface Free Energy Components of PMMAs Surface Calculated by Acid-Base Approach $\left(\mathrm{mJ} / \mathrm{m}^{2}\right)$. C) Surface Free Energy of PMMAs Surface Calculated by the Other Methods $\left(\mathrm{mJ} / \mathrm{m}^{2}\right)$. D) Polarity and Average Contact Angle

\begin{tabular}{|c|c|c|c|c|c|c|c|}
\hline \multicolumn{8}{|c|}{ A } \\
\hline Liquid & $\gamma \mathrm{L}$ & $\gamma L w L(\gamma d L)$ & $\mathrm{Y}^{\mathrm{ABL}}(\mathrm{\gamma pL})$ & $\mathrm{Y}^{+} \mathrm{L}$ & $\mathrm{Y}^{-} \mathrm{L}$ & \multicolumn{2}{|c|}{ Polarity ( $\left.\mathrm{\gamma}^{\mathrm{pL}} / \mathrm{ydL}\right)$} \\
\hline Water (w) & 72.8 & 21.8 & 51.00 & 25.5 & 25.5 & \multicolumn{2}{|c|}{2.34} \\
\hline Diiodomethane (d) & 50.8 & 50.8 & 0 & 0 & 0 & \multicolumn{2}{|c|}{0} \\
\hline Formamide (f) & 58.00 & 39.00 & 19.00 & 2.28 & 39.6 & \multicolumn{2}{|c|}{0.49} \\
\hline \multicolumn{8}{|c|}{ B } \\
\hline PMMAs & $\gamma \mathrm{L}$ & \multicolumn{2}{|c|}{ yLwL (ydL) } & \multicolumn{2}{|c|}{$\gamma^{A B L}(y p L)$} & $Y^{+} \mathrm{L}$ & $\mathrm{Y}^{-} \mathrm{L}$ \\
\hline $\mathrm{Q}$ & $39.77 \pm 0.76$ & \multicolumn{2}{|c|}{$35.19 \pm 0.76$} & \multicolumn{2}{|c|}{$4.58 \pm 0.48$} & 1.03 & 2.28 \\
\hline A & $36.60 \pm 1.28$ & \multicolumn{2}{|c|}{$32.71 \pm 2.56$} & \multicolumn{2}{|c|}{$3.88 \pm 1.74$} & 0.99 & 1.94 \\
\hline $\mathrm{D}$ & $37.71 \pm 1.45$ & \multicolumn{2}{|c|}{$34.72 \pm 0.89$} & \multicolumn{2}{|c|}{$2.99 \pm 1.12$} & 0.79 & 2.14 \\
\hline \multicolumn{8}{|c|}{ C } \\
\hline PMMAs & Equation of State & \multicolumn{2}{|c|}{ OWRK/Fowkes } & \multicolumn{2}{|c|}{ Wu } & \multicolumn{2}{|c|}{ Zisman } \\
\hline Q & $38.33 \pm 0.55$ & \multicolumn{2}{|c|}{$40.51 \pm 0.78$} & \multicolumn{2}{|c|}{$44.06 \pm 0.74$} & \multicolumn{2}{|c|}{$36.85 \pm 2.13$} \\
\hline$A$ & $35.81 \pm 0.90$ & \multicolumn{2}{|c|}{$37.39 \pm 1.09$} & \multicolumn{2}{|c|}{$40.95 \pm 0.98$} & \multicolumn{2}{|c|}{$32.27 \pm 8.98$} \\
\hline $\mathrm{D}$ & $36.75 \pm 1.14$ & \multicolumn{2}{|c|}{$38.62 \pm 1.45$} & \multicolumn{2}{|c|}{$42.09 \pm 1.45$} & \multicolumn{2}{|c|}{$35.58 \pm 2.23$} \\
\hline \multicolumn{8}{|c|}{ D } \\
\hline PMMAs & Polarity ( $\left.\mathrm{Y}^{\mathrm{PL}} / \mathrm{\gamma dL}\right)$ & \multicolumn{2}{|c|}{$\theta^{\circ}$ (Water) } & \multicolumn{2}{|c|}{$\theta^{\circ}$ (Diiodomethane) } & \multicolumn{2}{|c|}{$\theta^{\circ}$ (Formamide) } \\
\hline Q & $0.13 \pm 0.01$ & \multicolumn{2}{|c|}{$70.59 \pm 11.68$} & \multicolumn{2}{|c|}{$55.04 \pm 12.95$} & \multicolumn{2}{|c|}{$51.71 \pm 1.88$} \\
\hline A & $0.12 \pm 0.06$ & \multicolumn{2}{|c|}{$81.93 \pm 5.09$} & 52.72 & \pm 4.52 & 56.8 & 1.88 \\
\hline $\mathrm{D}$ & $0.08 \pm 0.03$ & 80.56 & \pm 3.35 & 49.18 & \pm 1.61 & 56.2 & 4.06 \\
\hline
\end{tabular}

According to the contact angle results, the wettability value of these resins was in the following order: Q-type (70.59) > D-type (80.56) > A-type (81.93) (Table 3D).

\section{Discussion}

The null hypothesis that denture base material type, chemical cleanser type, different concentration of chemical cleanser solution and polarity of resin would not interfere with $C$. albicans biofilm growth was rejected.

First, we evaluated the anticandidal effect of two alkaline peroxide denture cleansers, Corega ${ }^{\mathrm{TM}}$ and Fittydent $^{T M}$, and one neutral enzymatic peroxide denture cleanser, Polident $3 \mathrm{~min}^{\mathrm{TM}}$, on three different resins so their surfaces were standardized to avoid surface imbalance. The SEM and surface analyses were used in this stage. It is known that polyamide resin surfaces generally exhibit a rougher texture compared to PMMA resins ${ }^{6,12}$ and the surface structure may lead to increased microbial flora and the attenuated effect of cleansers ${ }^{1,24}$. However, we utilised a simple process to obtain standardized surface roughness from three types of resin with different surface properties and applied a smoothing method that adjusted their roughness to $0.32 \pm 0.02$ $\mu \mathrm{m}$ through a profilometer. However, even though a standardized surface roughness was used, all cells on the polyamide resin were very weakly attached to the surface and spontaneously separated more easily from the surface compared to PMMAs. These results showed that the surface properties of resins are not the only factor governing the $C$. albicans adhesion, and, at the same time, the chemical content of the material may affect the $C$. albicans adhesion (Table 1 ). That is why the Fittydent ${ }^{\mathrm{TM}}$ tablet had only anticandidal effects against biofilm on the D-type resin with the same administrative concentrations. In addition, the MTT analysis indicated that the polyamide resin with low polarity (Table 4D) exhibited a high anticandidal effect against $C$. albicans cells, whereas the PMMAs with high polarity had low anticandidal effect. The PMMAs, A-type resin, and Q-type resin exhibited approximately equal anticandidal effects, and one of the reasons may be that their polarity values were very close to one another. The bacterial attachment to resins has not been fully revealed to be affected by its SFE and wettability property because there are many inconsistent results from various studies ${ }^{8}$. For example, some studies showed a linear correlation between SFE values and C. albicans adhesion ${ }^{2,17}$, 
whereas other studies reported no correlation at $\mathrm{al}^{9,27}$. Likewise, in this study, we failed to find a strong correlation between SFE and C. albicans adhesion. It is speculated that low polarity, low SFE value and low wettability may lead to a significantly increased anticandidal effect. However, we found that merely the polarity feature of resins may alter its anticandidal affect. The SEM images substantially confirmed our speculations about resin types used in this study. For example, C. albicans biofilm layers on A- and Q-type resins were covered a much larger area and presented a higher level of growth than D-type resin. However, even though D-type resin showed rouger surface than the others, it can be pretty smooth and slippery following the surface deburring and polishing prosses. In addition, according to SEM presentations for all resins, we failed to find a significant difference between $C$. albicans forms such as yeast and hyphal formation.

Second, we conducted a MTT method to determine inhibitor concentration ( $\mathrm{IC}_{50} \mathrm{mg} / \mathrm{mL}$ ) and the minimum inhibitor concentration (MIC) values of these cleanser tablets. Results indicated that C. albicans viability was affected to alter the denture cleanser trademark, concentration, and resin type. Denture cleanser tablets act to biofilm layer in a concentration-dependent manner - that is, increasing the concentrations of denture cleanser tablets on biofilms layer lead to a gradual increase in the cell inhibition, showing a typical inhibitor effect. This means that the tablet concentrations are effective in terms of eliminating the biofilm layers. In addition, the concentration increasing effect reached maximum impact against cell viability at $64 \mathrm{mg} / \mathrm{mL}$ concentration (four $2.5 \mathrm{~g}$ effervescent tablets dissolved in $150 \mathrm{~mL}$ of water to prepare a $64 \mathrm{mg} / \mathrm{mL}$ solution). Regarding the efficacy of the tablets considered together with denture cleanser trademark and resin type, the Corega ${ }^{\mathrm{TM}}$ tablets should be advised to provide effective cleansing of A- and D-type resin ( $\mathrm{IC}_{50}, 30.42$ and $27.37 \mathrm{mg} / \mathrm{mL}$, respectively, correspond to approximately 2 tablets) and the Polident $3 \mathrm{~min}^{\mathrm{TM}}$ tablets are suggested for Q-type resin $\left(\mathrm{IC}_{50}, 22.78 \mathrm{mg} / \mathrm{mL}\right.$, correspond to approximately $1 \frac{1}{2}$ tablet). However, Fitty ${ }^{\mathrm{TM}}$ tablets must be used in a more concentrated manner for the same effect on biofilm layer when compared withother types ( $\mathrm{IC}_{50}, 38.19$ to $74.89 \mathrm{mg} / \mathrm{mL}$, correspond to approximately $2 \frac{1}{2}$ to $4 \frac{1}{2}$ tablets). Other studies also showed that the type of resin of denture base affects the amount of $C$. albicans biofilm layers colonization, as observed in this study ${ }^{4,6}$. Murata, et al. ${ }^{19}$ (2010) reported that the influence of neutral enzymatic denture cleanser on the surface properties was less than that of alkaline peroxide denture cleanser due to the neutral enzymatic denture cleanser containing less peroxide. However, none of the denture cleanser tablet concentrations were able to remove $C$. albicans biofilm completely in up to $25 \mathrm{mg} / \mathrm{mL}$ concentrations (approximately $1 \frac{1}{2}$ tablet). Most studies were conducted to remove $C$. albicans biofilm formation on the denture base resins of PMMAs via denture cleanser tablets ${ }^{15,29}$, whereas, to the best of our knowledge, a few studies evaluated the efficacy of denture cleansers on thermoplastic polyamide resin ${ }^{4,6}$. One of the thermoplastic polyamide resin studies demonstrated smaller C. albicans growth on the PMMA surface than on the thermoplastic polyamide resin ${ }^{4}$. They found that the residual monomer was released from the PMMA, and they were putting this forward as a serious theory. Therefore, in this study, specimens were soaked in distilled water for $24 \mathrm{~h}$ after polymerization to reduce the residual monomer. The cytotoxic effects of the acrylic resins remained at high levels within the first $24 \mathrm{~h}$ following polymerization ${ }^{28}$. The water immersion method was suggested to reduce the level of residual monomer ${ }^{11}$ because this toxic effect is reduced in a time-dependent manner ${ }^{29}$. Another study determined that the cleanser tablets tested were more effective for PMMA resin than for thermoplastic polyamide resin ${ }^{6}$. This result was inconsistent with our findings. The reason we applied the surface roughness process to the resins using a profilometer was because of the varying study findings for both resins.

\section{Conclusion}

We have clearly demonstrated that the polarity of resins and the chemical content of the cleanser may affect $C$. albicans biofilm adhesion. Also, the results clearly describe a high anticandidal effect that is directly dependent on the concentrations of tablets. Our finding suggested that the Polident $3 \mathrm{~min}^{\mathrm{TM}}$ and Corega $^{\mathrm{TM}}$ tablets are suitable for patients who use any denture resin types, whereas the Fittydent ${ }^{\mathrm{TM}}$ tablet should only be advised for D-type resin users, and each cleanser solution should be prepared by two tablets and with $150 \mathrm{~mL}$ water. In summary, it 
was shown that anticandidal activity appears to be a function of the nature of the resins, their roughness, the type of cleanser and the specific concentrations of the cleanser.

\section{Acknowledgments}

The authors are thankful to Dr. Şaban Tekin and Dr. Isa Karaman for generous assistance, and to the Gaziosmanpaşa University Research Foundation (Grant 2014/90) for financial support.

\section{References}

1- Berger JC, Driscoll CF, Romberg E, Luo Q, Thompson G. Surface roughness of denture base acrylic resins after processing and after polishing. J Prosthodont. 2006;15(3):180-6.

2- Busscher HJ, Weerkamp AH, van der Mei HC, van Pelt AW, de Jong $\mathrm{HP}$, Arends J. Measurement of the surface free energy of bacterial cell surfaces and its relevance for adhesion. Appl Environ Microbiol. 1984;48(5):980-3.

3- Dills SS, Olshan AM, Goldner S, Brogdon C. Comparison of the antimicrobial capability of an abrasive paste and chemical-soak denture cleaners. J Prosthet Dent. 1988;60(4):467-70.

4- Fernandes FS, Pereira-Cenci T, Silva WJ, Ricomini AP Filho, Straioto FG, Del Bel Cury AA. Efficacy of denture cleansers on Candida spp. biofilm formed on polyamide and polymethyl methacrylate resins. Prosthet Dent. 2011;105(1):51-8.

5- Ferreira MA, Pereira-Cenci T, Vasconcelos LM, Rodrigues-Garcia RC, Del Bel Cury AA. Efficacy of denture cleansers on denture liners contaminated with Candida species. Clin Oral Investig. $2009 ; 13(2): 237-42$.

6- Freitas-Fernandes FS, Cavalcanti YW, Ricomini AP Filho, Silva WJ, Cury AADB, Bertolini MM. Effect of daily use of an enzymatic denture cleanser on Candida albicans biofilms formed on polyamide and poly (methyl methacrylate) resins: an in vitro study. J Prosthet Dent. 2014;112(6):1349-55.

7- Ghalichebaf M, Graser GN, Zander HA. The efficacy of denturecleansing agents. J Prosthet Dent. 1982;48(5):515-20.

8- Hahnel S, Rosentritt M, Burgers R, Handel G, Lang R. Candida albicans biofilm formation on soft denture liners and efficacy of cleaning protocols. Gerodontology. 2012;29(2):e383-91.

9- Hahnel S, Rosentritt M, Handel G, Burgers R. In vitro evaluation of artificial ageing on surface properties and early Candida albicans adhesion to prosthetic resins. J Mater Sci Mater Med. 2009;20(1):24955.

10- Jagger DC, Harrison A, Jandt KD. The reinforcement of dentures. J Oral Rehabil. 1999;26(3):185-94.

11- Jorge JH, Giampaolo ET, Machado AL, Vergani CE. Cytotoxicity of denture base acrylic resins: a literature review. J Prosthet Dent. 2003;90(2):190-3.

12- Kawara $M$, Iwata $Y$, Iwasaki M, Komoda $Y$, Iida $T$, Asano $T$, et al. Scratch test of thermoplastic denture base resins for non-metal clasp dentures. J Prosthodont Res. 2014;58(1):35-40.

13- Kulak Y, Arikan A, Albak S, Okar I, Kazazoglu E. Scanning electron microscopic examination of different cleaners: surface contaminant removal from dentures. J Oral Rehabil. 1997;24(3):209-15.

14- Kulak-Ozkan Y, Kazazoglu E, Arikan A. Oral hygiene habits, denture cleanliness, presence of yeasts and stomatitis in elderly people. J Oral Rehabil. 2002;29(3):300-4.

15- Lucena-Ferreira SC, Ricomini-Filho AP, Silva WJ, Cury JA, Cury $A A$. Influence of daily immersion in denture cleanser on multispecies biofilm. Clin Oral Investig. 2014;18(9):2179-85.

16- McCabe JF, Murray ID, Kelly PJ. The efficacy of denture cleansers. Eur J Prosthodont Restor Dent. 1995;3(5):203-7.

17- Minagi S, Miyake $Y$, Inagaki K, Tsuru H, Suginaka H. Hydrophobic interaction in Candida albicans and Candida tropicalis adherence to various denture base resin materials. Infect Immun. 1985;47(1):11-4 18- Minagi S, Tsunoda T, Yoshida $\mathrm{K}$, Tsuru $\mathrm{H}$. Objective testing of the efficiency of denture-cleansing agents. J Prosthet Dent. 1987; 58(5):595-8.

19- Murata H, Chimori $\mathrm{H}$, Hong G, Hamada T, Nikawa H. Compatibility of tissue conditioners and denture cleansers: influence on surface conditions. Dent Mater J. 2010;29(4):446-53.

20- Nikawa $\mathrm{H}$, Hamada $\mathrm{T}$, Yamamoto T. Denture plaque: past and recent concerns. J Dent. 1998;26(4):299-304.

21- Nikawa $\mathrm{H}$, Hamada $\mathrm{T}$, Yamashiro $\mathrm{H}$, Kumagai $\mathrm{H}$. A review of in vitro and in vivo methods to evaluate the efficacy of denture cleansers. Int J Prosthodont.1999;12(2):153-9.

22- Nikawa H, Iwanaga $\mathrm{H}$, Hamada $\mathrm{T}$, Yuhta S. Effects of denture cleansers on direct soft denture lining materials. J Prosthet Dent. 1994;72(6):657-62

23- Peracini A, Davi LR, Ribeiro NQ, Souza RF, Silva CH, Freitas Oliveira Paranhos $\mathrm{H}$. Effect of denture cleansers on physical properties of heat-polymerized acrylic resin. J Prosthodont Res. 2010;54(2):78-83. 24- Radford DR, Sweet SP, Challacombe SJ, Walter JD. Adherence of Candida albicans to denture-base materials with different surface finishes. J Dent. 1998;26(7):577-83.

25- Rodford R. The development of high impact strength denture-base materials. J Dent. 1986;14(5):214-7.

26- Sato S, Cavalcante MR, Orsi IA, Paranhos HF, Zaniquelli $\mathrm{O}$ Assessment of flexural strength and color alteration of heat-polymerized acrylic resins after simulated use of denture cleansers. Braz Dent J. 2005; 16(2):124-8.

27- Serrano-Granger C, Cerero-Lapiedra R, Campo-Trapero J, Del Rio-Highsmith J. In vitro study of the adherence of Candida albicans to acrylic resins: relationship to surface energy. Int J Prosthodont. 2005; 18(5):392-8.

28- Sheridan PJ, Koka S, Ewoldsen NO, Lefebvre CA, Lavin MT. Cytotoxicity of denture base resins. Int J Prosthodont. 1997;10(1):73-

29- Silva FC, Kimpara ET, Mancini MN, Balducci I, Jorge AO, Koga-Ito CY. Effectiveness of six different disinfectants on removing five microbial species and effects on the topographic characteristics of acrylic resin. J Prosthodont. 2008;17(8):627-33.

30- Yunus N, Rashid AA, Azmi LL, Abu-Hassan MI. Some flexural properties of a nylon denture base polymer. J Oral Rehabil. 2005;32(1):65-71. 